\title{
HINDOSTAANSE MUZIEKINSTRUMENTEN EN ZANG IN SURINAME
}

Tussen 1873 en r916 immigreerden er in Suriname ruim 34.000 Hindostanen, die moesten voorzien in het toen heersende gebrek aan arbeidskrachten. Ondanks aanvankelijk ongunstige levensomstandigheden - o.a. zwaar werk op de plantages, dat nauwelijks van slavernij verschilde en een groot tekort aan vrouwen zodat een normaal familie-leven onmogelijk was - slaagden de immigranten erin zich als een aparte groep te handhaven. $\mathrm{Zij}$ behielden een eigen cultuur, hetgeen o.a. tot uiting komt in een eigen religie (Hindo en Moslim), taal, muziek, traditie en moraal. Het spreekt vanzelf dat de specifiek Hindostaanse culturele omstandigheden in de loop der jaren in Suriname veranderingen ondergingen.

De aard van deze veranderingen kan onder meer worden geillustreerd door de geschiedenis van de Hindostaanse muziek in Suriname. Het waren echter niet alleen de veranderingen in de muziek die de schrijver brachten tot het opstellen van het hierna volgende overzicht. Er waren nog twee andere redenen. In de eerste plaats bestaat er tot op heden noch in Suriname, noch in Nederland, enige literatuur betreffende Surinaams-Hindostaanse muziek en zang. De enige die enkele woorden hieraan wijdde was dr. J. H. AdHIN in zijn woordenboek Hindi-Nederlands. Helaas gaf hij soms een minder juiste vertaling. In de tweede plaats bleek de schrijver, die sinds jaren leider is van de 'Surinaamse Kauwali Band' in Den Haag, dat het bestaan van deze band - die zeer populair is bij de ongeveer 3000 in Nederland verblijvende Surinaamse Hindostanen - en van de muziek die zij speelt, in Nederland praktisch onbekend is.

In het hierna volgende wordt een overzicht gegeven van de verschillende soorten zang, en - in alfabetische volgorde - van de 
muziekinstrumenten welke in Suriname door de Hindostanen (Hindo en Moslim) worden bespeeld.

Tot de komst van de Hindostaanse film in Suriname, ongeveer twintig jaar geleden, werd in Suriname naast Tjautaal en Ramajan ook nog Bhadjan, Bierha en in het bijzonder Baithak ké gana gezongen.

Tjautaal, dat wordt gezongen met begeleiding van dhool, djhaadjh en kartaal, is een lied dat gezongen wordt bij het Holi-feest, dat overeenkomt met het Europese oudejaarsfeest, met dien verstande dat op die dag ook de verdelging van het kwade plaats vindt (Holyka dahan).

Ramajan is de gezongen tekst uit de Ramayana. Het wordt gezongen bij spel van de nagara en de djhaadjh. In plaats van de nagara wordt ook op de dhool gespeeld.

Bhadjan wordt gespeeld en gezongen bij dhool, khadjarie en kartaalspel.

De Baithak ké gana was in feite de populairste van allemaal. Hierbij werd een lied met een bepaalde strekking (filosofie, godsdienst, liefde, enz.) gezongen, dat altijd begeleid werd door dhool, sarangie en madjiera.

De Bierha is een ballade, uitsluitend gezongen door mannen, en begeleid door de nagara.

Naast deze gezangen had men nog het Natak (Hindostaanse operette).

$\mathrm{Na}$ de komst van de Hindostaanse film in Suriname raakte het Surinaams Hindostaanse toneel (operette) op de achtergrond. Het filmlied deed vanaf toen definitief zijn intrede in Suriname en de populaire Baithak ké gana versmolt met de Kauwali, en werd ook voortaan meer en meer zo genoemd. Kawwali, dat uit zang bestaat met instrumentale begeleiding van dhool, harmonium en dhantaal komt uit het vroegere Brits-Indië en werd uiteraard het meest door daarvandaan geïmporteerde films geïntroduceerd.

Sinds omstreeks r950 komen in Suriname voornamelijk twee soorten zang met muziek voor, te weten filmliederen op muziek en de kauwali, waarbij meestal een verhaal verteld wordt op muziek.

Bij de begeleiding van de hierboven genoemde soorten zang, 
wordt een aantal muziekinstrumenten gebruikt, die in het hiernavolgende kort worden beschreven.

De dandtaal is een heel eenvoudig van staal vervaardigd slaginstrument. Het bestaat uit twee delen, die er uitzien als de staf van Sinterklaas en een hoefijzer. Het hoefijzervormige metalen voorwerp waarmee de staf bespeeld wordt is ca. $20 \mathrm{~cm}$ hoog. De staf heeft een diameter van ongeveer $\mathrm{I} \mathrm{cm}$ en is meestal ruim een meter lang. De dandtaal heeft een staalachtige klank.

Vroeger werd dit instrument alleen door mannen bespeeld, zoals alle Hindostaans-Surinaamse muziekinstrumenten behalve de dhool en het harmonium. Tegenwoordig echter gebeurt dit ook door vrouwen. De dandtaal wordt altijd in combinatie gespeeld met dhool en harmonium. Dit zijn eigenlijk ook de drie instrumenten waarmee tegenwoordig de Surinaamse kauwalie-zang wordt begeleid.

De dhool is eenvoudig van constructie en heeft ongeveer de vorm van de Cubaanse conga, d.w.z. het is een slaginstrument bestaande uit een naar beide zijden taps toelopende holle houten cilinder, aan beide zijden bespannen door in het algemeen resp. een geiteen een bokkevel, het kleine vel is blank van kleur. Het instrument wordt aan beide zijden tegelijk bespeeld met gekromde vingers, met vlak gehouden vingers, met de handpalm en ook met de muis van de hand.

Het holle lichaam van de dhool wordt uit hout vervaardigd. In Suriname gebruikt men hiervoor voornamelijk het hout van de mangoboom, de broodboom en het zg. mierenhout. De vellen van de dhool worden opgerold om een bamboe hoepel, daarna worden ze gespannen door middel van touw. Aan de binnenzijde van het grote vel worden verschillende olieën en gemalen kruiden gesmeerd, zoals wonderolie, fenegriek, etc. Hierdoor onstaat een betere klank, bovendien blijft hierdoor het geluid langer naklinken. De dhool wordt aan de zijde van het kleine vel op een bepaalde toonhoogte gestemd. Dit stemmen geschiedt door middel van ringen, die schuiven om telkens twee van de spantouwen. Het lichaam van de dhool wordt vaak mooi afgeschilderd en soms van snijwerk voorzien. Meestal wordt de dhool rood geverfd. De kleur heeft een religieuze betekenis, rood is namelijk de kleur van de god Hanoeman. De dhool wordt om de hals gebonden (dit komt in Suriname echter practisch niet voor), om het middel gebonden 
of bij de kleermakerszit onder het scheenbeen vastgeklemd bespeeld, uiteraard steeds met de dhool in liggende stand.

De dhool is het geliefdste slaginstrument in Suriname. Hij wordt daar zowel door de man als door de vrouw bespeeld. De dhoolbespeler wordt in Suriname als tabla-maastar betiteld, waarschijnlijk omdat de dhool familie is van de tabla (het beroemde klassieke slaginstrument van India), welke in Suriname niet zo vaak gespeeld wordt, door gebrek aan leermeesters en omdat het spel jarenlange en voortdurende studie vergt. Sinds de komst van de Heer AKaL, die jarenlang in India heeft gestudeerd, alsmede door de komst van beroemde Indiase tabla-spelers bekend van de Indiase film, is momenteel de animo om tabla te spelen sterk toegenomen.

De dhool is in Suriname onmisbaar bij het musiceren. De vrouwen gebruiken dit slaginstrument bij geboortefeesten, zoals tjha-thie (feest op de zesde dag na de geboorte) en barhie (feest op de twaalfde dag na de geboorte), waarbij aangetekend moet worden dat alleen de geboorte van zonen en niet die van dochters gevierd wordt. Voorts bespelen zij hem bij huwelijksfeesten, zoals matmangra (een offerfeest van vrouwen ten behoeve van een huwelijksvoltrekking) en bij bhat-waan (bij dit feest wordt rijst aan de halm geroosterd). Mannen bespelen de dhool o.a. bij godsdienstige liederen (bhadjan), bij kauwalie zang, bij toneeluitvoeringen, bij ramajan-zang en bij tjautaal.

De djhaadjh bestaat uit twee ronde metalen bekkens van brons of een zuiver metaal. De bekkens hebben dezelfde grootte met een diameter van ongeveer II cm. In het midden heeft de djhaadjh een verhoging waarin een touw of riempje is aangebracht. Aan het touw is een opgerolde doek bevestigd als handvat. Deze 'kussentjes' worden volledig in de handpalm vastgehouden, zodanig dat de djaahdjh rust op de tweede kootjes van de vingers.

De djhaadjh is zodanig geconstrueerd dat tijdens het bespelen alleen de randen elkaar raken en trillen als ze langs of tegen elkaar geslagen worden. De klank is een beetje te vergelijken met het geluid van een rijdende trein en is zeer doordringend.

De djhaadjh wordt uitsluitend door mannen gespeeld bij ramajan-zang en de tjautaal.

Het harmonium behoort tot de familie der blaasinstrumenten. Hoewel er harmoniums zijn van kleiner en groter formaat, hebben ze toch alle een gelijk bereik van $3 \frac{1}{2}$ octaaf. Men kan het een huis- 
orgel noemen, dat men na het bespelen kan opvouwen en als een koffer overal gemakkelijk meenemen.

Een harmonium heeft doorslaande tongen. Zodra in de ruimte waarin de tong zich bevindt, wordt geblazen, begint deze tong te trillen. Door deze trilling ontstaat de toon. Met de ene hand bedient men de blaasbalg voor de luchttoevoer naar de tongen, met de andere hand wordt op de toetsen - gelijk aan pianotoetsen - de gewenste melodie gespeeld.

Het harmonium is voor de Hindostanen een even belangrijk muziekinstrument, als de piano voor de Europeanen. Op het harmonium kunnen alle westerse accoorden gespeeld worden. De klank heeft echter een eigen kleur, zodat deze niet te vergelijken is met de klank van Europese muziekinstrumenten. Zowel legato als staccato is zeer goed mogelijk. Zeer belangrijk is nog de mogelijkheid van crescendo en decrescendo.

Het harmonium kan bij iedere Hindostaanse muziek en zang worden gebruikt. De toon is chromatisch in halve tonen onderverdeeld, zodat dit voor een Europeaan geen probleem kan vormen. Het harmonium wordt zowel door mannen als door vrouwen bespeeld.

De Haagse Kauwalie Band gebruikt vaak heel eenvoudige ritmen. De melodie en de woorden, die gezongen worden, zijn in het algemeen niet moeilijk. Deze drie elementen (ritme, melodie en tekst) vormen één geheel. Ook de dynamiek moet men bij de kauwalie-zang en muziek heel goed beheersen.

Gedurende de zang is de instrumentale begeleiding secundair. $\mathrm{Na}$ het eerste couplet van de zang wordt de begeleiding primair, waarbij door de musici eventueel mag worden geïmproviseerd. De improvisatie moet kort zijn. Het bovenstaande herhaalt zich tot het lied eindigt. Meestal eindigt deze zang met het refrein of met de eerste regel. Na een driemaal door de dhool gegeven signaal moet men echter abrupt ophouden.

De kartaal is een groot soort castagnetten. Hij is eenvoudig van constructie, en bestaat uit twee houten delen, waarin losse metalen schijven gevat zijn, bovendien zijn aan de twee delen bellen bevestigd. Het hout wordt meestal rood geverfd. Elk deel is een langwerpig stuk plat hout van ca. $2 \mathrm{~cm}$ dikte en overige afmetingen ca. 30 bij $10 \mathrm{~cm}$. In elk plankje is een gat gemaakt waardoor de vier vingers van de hand gestoken kunnen worden. Men houdt de twee delen in een hand met de vier vingers door het gat van het ene plankje en de duim door het andere plankje. Een 
speler houdt in elke hand een kartaal. Door de twee delen van de kartaal tegen elkaar te drukken en weer los te laten ontstaat er een rinkelend en duidelijk ritmisch effect.

De kartaal wordt gespeeld bij ramajan en bhadjan. De kartaal wordt in Suriname uitsluitend door mannen bespeeld. De ramajan en bhadjan worden ook uitsluitend door mannen gezongen.

De khadjarie komt overeen met de tamboerijn. Hij bestaat uit een houten ring van ca. $20 \mathrm{~cm}$ doorsnede, waarop een leguaan-vel is gelijmd. Indien de khadjarie in de linkerhand vastgehouden wordt, dan wordt met de vingers en de handpalm van de rechterhand het door de zanger aangegeven ritme op het vel geslagen. Aan de rand van het instrument bevinden zich losse metalen schijfjes die met de duim van dezelfde hand worden gerinkeld. De linkerhand kan dan nog door drukken op het vel bepaalde klankeffecten teweegbrengen.

Bij de khadjarie wordt bhadjan gezongen. De bhadjan wordt begeleid door khadjarie, dhool en kartaal. De khadjarie-spelers zitten in twee rijen van tenminste vier personen tegenover elkaar en zingen beurtelings bhadjan, met dien verstande dat de tweede groep telkens herhaalt wat de eerste groep gezongen heeft. Opzij van de groepen wordt de dhool gespeeld, die het tempo aangeeft. Aan de andere zijde wordt de kartaal bespeeld, waarvan de speler af en toe bhadjan-zang afwisselt met het zingen van kabier. De kabier is een enigszins ironisch lied met een bepaalde moraal.

Een bhadjan inclusief de tussengevoegde kabiers duurt ongeveer een half uur. Meestal wordt de ene bhadjan na de andere gezongen; dit kan een gehele nacht duren. De bhadjans worden veelal na een godsdienstige plechtigheid gezongen, zoals na khatha en bhaagwat. De bhadjans worden ook vaak gezongen door de kabierpanthie's, d.w.z. volgelingen van de Kabier secte.

De madjiera komt in enige opzichten overeen met de cymbaal. Hij bestaat uit twee even grote van een zuiver metaal (bijv. koper) vervaardigde klokken zonder klepel ter grootte van een fietsbel. In het midden hebben ze een gat, waarin een stevig touw is aangebracht, waardoor de twee madjiera's éen geheel vormen. Het touw wordt goed vast om de middelvingers gewonden, zodat beide madjiera's in beide handēn goed in de greep zitten. De klank ontstaat als de madjiera's tegen elkaar geslagen worden. De madjiera klinkt als klokkenspel in een versneld tempo, enigszins te vergelijken met de klank van een fietsbel. 
De madjiera wordt in Suriname altijd samen met de sarangie en de dhool gespeeld. De madjiera wordt dus nooit alleen gespeeld. De laatste tijd wordt hij erg weinig gespeeld.

De nagara is een belangrijk slaginstrument voor de Surinaamse Hindostanen en benadert in vorm de pauk. Hij bestaat uit twee bekkens van ca. $35 \mathrm{~cm}$ hoogte, waarbij de grote nagara een diameter van $45 \mathrm{~cm}$ heeft en de kleine nagara een doorsnede van $25 \mathrm{~cm}$.

De nagara is vrij ingewikkeld van constructie; de grote wordt gemaakt van klei of hout; klei geeft een betere klank. Een van de twee bekkens van de nagara moet bespannen zijn met een bokkevel en het andere deel met een geite-vel. Het vel wordt gewikkeld om een hoepel van Indisch bamboe. Aan deze hoepel zijn touwen of riemen gespannen die anderzijds bevestigd zijn aan een metalen ring of een riem, die onderaan het bekken klemt. De toonhoogte wordt gefixeerd door het vel bij vuur te verwarmen en door ringen die elk over twee touwen schuiven. Het vel van de grote nagara wordt in het midden aan de binnenkant ingesmeerd met een smeersel van plantenkruiden en olie, zoals onder meer wonderolie, fenegriek en karail. De ingesmeerde plek heeft een diameter van ca. $7 \mathrm{~cm}$. Het smeersel wordt aangebracht als een koek die in het midden bijna een halve centimeter dik is en naar de rand toe plat afgevlakt. De koek droogt in, blijft vastzitten aan het vel en zorgt ervoor dat de klank langer aangehouden wordt.

De kleine nagara heeft een blank vel en geeft een hogere toon. Hij wordt altijd van hout geconstrueerd. Het vel wordt op dezelfde manier gespannen als bij de grote nagara, doch wordt niet ingesmeerd. De nagara wordt op een kussen (bietha) op de grond geplaatst om hem te kunnen bespelen, de bekkens hebben een enigszins schuine stand, de kleine nagara het sterkst hellend. Het bespelen geschiedt met twee stokken van ca. $30 \mathrm{~cm}$ lengte maar van verschillende dikte waarmee beide nagara's bespeeld worden.

Met begeleiding van de nagara wordt in Suriname de bierha gezongen. De bierha is een ballade die uitsluitend door mannen gezongen wordt. Vroeger behoorden de zangers respectievelijk dansers bij de bierha tot de kaste van de ahiers oftewel herders van koeien. De dans na het zingen van ieder couplet van de bierha heet arhierwa(n) ké naatj. De bierha heeft een vastgesteld ritme. $\mathrm{Na}$ het zingen van een couplet van de bierha wordt het ritme aan de nagartjie (nagara-bespeler) overgelaten, die in staat is zijn ritme onmiddellijk verder te improviseren. Tijdens deze improvi- 
satie wordt de ahierwa ké naatj gedanst. De nagara-speler zorgt er voor na zijn improvisatie weer terug te komen in zijn oorspronkelijk ritme, waarna de zanger zijn bierha kan voortzetten.

Bierha's worden in Suriname bij huwelijksfeesten zeer vaak gezongen, uiteraard met begeleiding van de nagara. De bierha wordt in Suriname ook door de daphala begeleid. De daphala komt overeen met de tamboerijn.

De sarangie is een strijkinstrument dat in vele opzichten vergelijkbaar is met een viool; de bovenzijde van de klankkast bestaat echter uit een gespannen vel. De constructie is tamelijk ingewikkeld. Het instrument wordt uit hout vervaardigd en bestaat uit de volgende onderdelen: I, krul; 2, stemschroeven; 3 , kielhoutje; 4, hals; 5 , tokkeltoets in de hals; 6 , met vel bespannen klankkast; 7 , kam (stukje hout tussen snaren en vel). De klankkast is aan de bovenkant bespannen met geite-vel waarover de snaren worden gespannen.

Er zijn twee snaren waarop de melodie wordt gespeeld en een aantal meeklinkende snaren. Het aantal snaren dat meeklinkt is meestal oneven, maar in ieder geval meer dan vijf. De snaren waarop de melodie wordt gespeeld worden aangestreken door een zelfgemaakte strijkstok, die in bepaalde opzichten lijkt op een cellostok. De strijkstok bestaat uit hout en uit geprepareerd of gewoon paardehaar. Het haar wordt met hars ruw gemaakt opdat haar en snaren zo intens mogelijk contact zullen hebben. De strijkstok is even belangrijk als het instrument zelf.

$\mathrm{Bij}$ het bespelen wordt de sarangie staande geplaatst in een stoffen riem om het middel. De speelwijze is te vergelijken met die van de cello. De strijkstok wordt in de ondergreep gehouden.

De sarangie heeft een volle en doordringende klank. Men bespeelt dit instrument bij volksdansen en klassieke liederen, de laatste tijd minder dan vroeger.

De doelstelling van de 'Surinaamse Kauwali Band' is de SurinaamsHindostaanse (Hindo en Moslim) cultuur, speciaal ten aanzien van zang en muziek te propageren. Deze band houdt zich daarom gaarne aanbevolen voor het geven van demonstraties. (Contactadres: S. BiHARIE, Elsstraat i6 's-Gravenhage). 
HINDOSTAANSE MUZIEK IN SURINAME

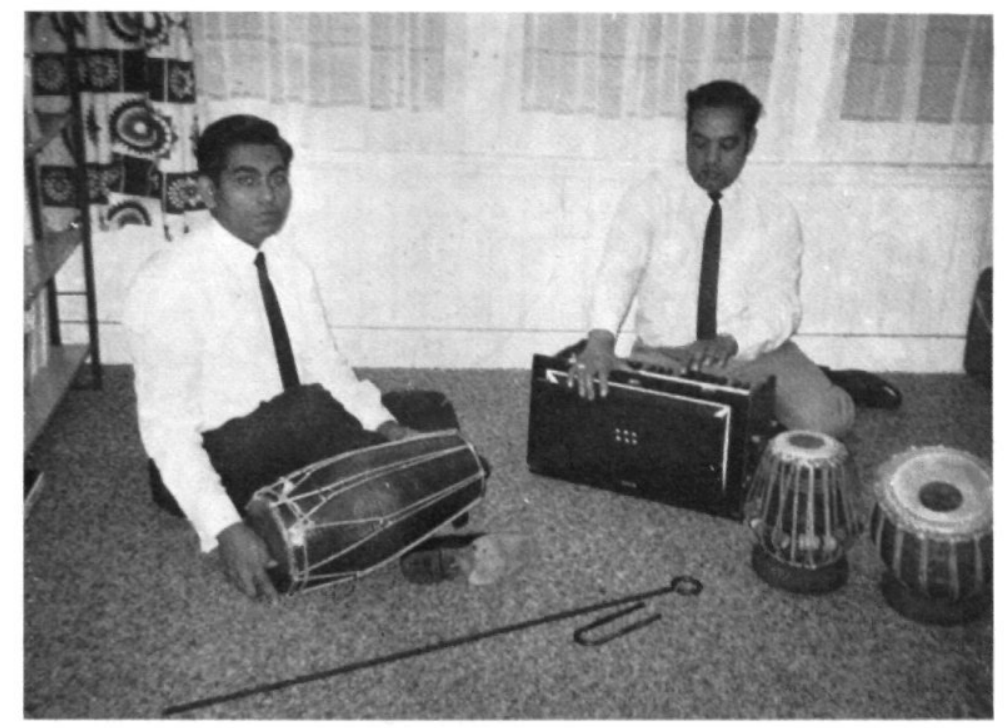

Fig. I. Twee leden van de 'Surinaamse Kauwali Band' in Den Haag met enkele van hun instrumenten: dandtaal (voorgrond), dhool (links), harmonium en twee soorten van tabla.

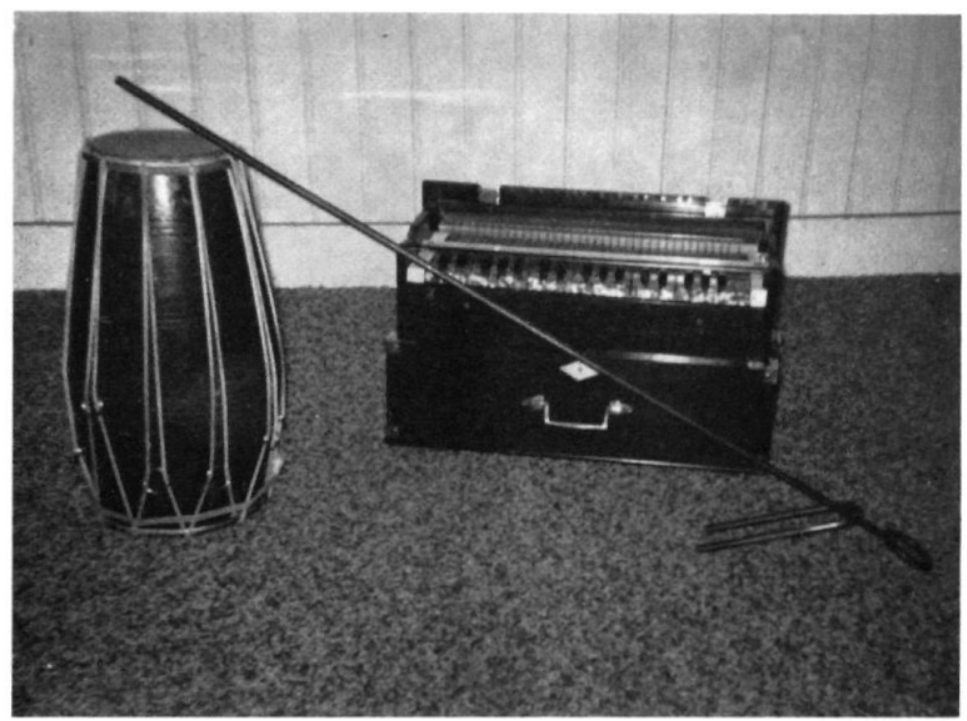

Fig. 2. De drie muziekinstrumenten welke door de Hindostaanse musici in Suriname het meest bij de baithak ké gana worden gebruikt: dhool, dandtaal en harmonium. 